\title{
A ORGANIZAÇÃO MUNDIAL DO COMÉRCIO COMO ESPAÇO DE LUTA DO LIBERALISMO NA PERSPECTIVA DA NOÇÃO DE CAMPO DE PIERRE BOURDIEU'
}

\author{
THE WORLD TRADE ORGANISATION AS A PLACE OF FIGHTING OF \\ LIBERALISM FROM THE PERSPECTIVE OF THE NOTION OF FIELD BY \\ PIERRE BOURDIEU
}

DOI: $10.5380 / \operatorname{cg} . v 10 i 2.79326$

Olga Nancy Peña Cortés ${ }^{2}$

João Francisco Cortes Bustamante3

\begin{abstract}
Resumo
No século XIX, na Europa, o liberalismo encontra ambiente favorável para se difundir junto com a democracia e o capitalismo. No século XX, os Estados Unidos tornam-se o marco do modelo liberal-democrático e iniciam um processo de institucionalização mundial. A Organização Mundial do Comércio, como proposta liberal econômica, expõe a disputa de poder por parte dos Estados Unidos, da União Europeia e da China. Analisa-se a prática do eixo filosófico-econômico-político em que orbitam Estados Unidos, China e União Europeia nessa organização com base na noção de campo do pensador Pierre Bourdieu. Pretende-se avaliar como espaço social constituído por agentes sociais - países membros - em que posições ocupadas sinalizam a rede interacional que mantém e conserva os interesses dos seus principais agentes. $\mathrm{O}$ artigo privilegia a análise teóricoconceitual por meio de bibliografia e o método analítico-filosófico com vistas a oferecer reflexões sobre as relações de agentes sociais no âmbito das instituições internacionais.
\end{abstract}

Palavras-Chave: Campo; OMC; Liberalismo; Teoria bourdieusiana.

\begin{abstract}
In the 19th (nineteenth) century, in Europe, liberalism found a favourable environment to spread along with democracy and capitalism. In the 2oth (twentieth) century, the United States became the landmark of the liberal-democratic model and began a process of worldwide institutionalization. The World Trade Organisation, as a liberal economic proposal, exposes the power dispute between the United States, the European Union and China. The practice of the philosophical-economic-political axis in which the United States, China and the European Union orbit in this organisation is analysed based on the notion of the field of the thinker Pierre Bourdieu. It is intended to evaluate how social place constituted by social agents - member countries - in which occupied positions signal the interactional network that maintains and conserves the interests of its main agents. The article privileges the theoretical-conceptual analysis through bibliography and the analytical-philosophical method with a view to offering reflections about the relations of social agents within international institutions.
\end{abstract}

Keywords: Field; WTO; Liberalism; Bourdieu's theory.

\footnotetext{
${ }^{1}$ Este artigo está licenciado sob a Licença Creative Commons Attribution (CC BY 4.0), sendo permitido o compartilhamento com reconhecimento da autoria e publicação inicial nesta revista.

2 Doutoranda pelo Programa de Pós-Graduação em Filosofia da Pontifícia Universidade Católica do Rio Grande do Sul. E-mail: olga.cortes@acad.pucrs.br. ORCID: https://orcid.org/o0o0-0001-6203-6453.

3 Mestrando pelo Programa de Pós-Graduação em Filosofia da Pontifícia Universidade Católica do Rio Grande do Sul. E-mail: https://orcid.org/o000-0002-2069-6506. ORCID: joao.bustamante@edu.pucrs.br.
} 


\section{INTRODUÇÃO}

Antes de expor de forma mais acurada o tema proposto pelo artigo, cabe ofertar uma breve consideração quanto à compreensão sobre o liberalismo. Entre os séculos XVIII e XIX, a ascensão da burguesia conjuntamente com o modo econômico capitalista favorece o liberalismo econômico na Europa tendo como símbolo a Revolução Industrial, no século XIX, na Grã-Bretanha (HOBSBAWM, 2002). A expansão territorial e populacional dos Estados Unidos, na segunda metade do século XIX, beneficia o liberalismo econômico de modo associado à democracia e à igualdade (HOBSBAWM, 1996).

O liberalismo político e econômico, entretanto, recrudesce e se enfraquece, no século XX, entre a I Guerra Mundial e a II Guerra Mundial com a assunção ao poder político de regimes fascistas e comunistas. Embora com matizes econômicos e, algumas vezes, políticos distintos de país a país, o fascismo e o comunismo conduziram à queda do modelo liberal-democrático no continente europeu entre as guerras (HOBSBAWM, 2003). Após o término da II Guerra Mundial, o modelo liberaldemocrático assume nos Estados Unidos a face mais incisiva desse modelo em uma conciliação de proposta econômica e política com viés de institucionalização mundial (PECEQUILO, 2003).

Nesse arcabouço, o objetivo deste artigo é apresentar a Organização Mundial do Comércio $\mathrm{OMC}$ - como um ambiente institucional da proposta liberal econômica em conjunto com a crescente disputa por espaço de poder entre Estados Unidos, China e União Europeia. Ao ser um espaço negociador, a OMC transforma-se cada vez mais em um espaço de lutas por poder econômico e político do que um espaço facilitador para a expansão da proposta liberal econômica. Tal transformação nos instiga a recorrer ao legado do filósofo e sociólogo francês Pierre Bourdieu (19302002) para fundamentar e exercitar o paralelo conceitual teórico por meio da noção de campo, de forma que possamos configurar uma análise prática do eixo filosófico-econômico-político em que orbitam Estados Unidos, China e União Europeia no âmbito da OMC. A escolha pela noção de campo recai pela possibilidade que nos oferece de analisar a OMC como um espaço social constituído por agentes sociais - países membros -, cujas posições ocupadas sinalizam a rede interacional que mantém e conserva os interesses dos seus principais agentes.

Para alcançar nosso objetivo, nos valemos da análise teórico-conceitual por meio da bibliografia e do método analítico-filosófico com vistas a ofertar reflexões sobre as relações de agentes sociais no âmbito das instituições internacionais. Alerta-se, no entanto, para os limites de tal proposta na medida em que o ensejo é o de trazer para o âmbito das Relações Internacionais um exercício especulativo filosófico sustentado na teoria social bourdieusiana à luz de uma das noções constitutivas de seu construto teórico. Nesse sentido, a proposta aqui apresentada não pretende nem esgotar o tema nem ofertar uma análise fechada, mas inspira um ponto de partida possível para futuras pesquisas. Com tal intuito, apresentaremos duas seções e, após, uma reflexão conclusiva. A primeira seção dedica-se a delinear o arcabouço teórico de Pierre Bourdieu, destacando de sua teoria 
a noção de campo. A segunda seção oferece um percorrido histórico da OMC com seus principais preceitos liberais constituintes. As reflexões conclusivas expõem, em exercício prático com os agentes internacionais envolvidos, Estados Unidos, China e União Europeia, como o espaço de luta da referida instituição não acarreta subversão da posição de poder particular enquanto se mantém uma cumplicidade pela manutenção da ação de cada agente partícipe dessa organização.

\section{PIERRE BOURDIEU E A NOÇÃO DE CAMPO}

Pierre Bourdieu (1930-2002), filósofo e sociólogo francês, elabora uma teoria do mundo social, a qual contempla a complexa relação entre agente (pessoas e instituições) e meio social. O amplo construto teórico que apresenta visava acima de tudo uma transcendência prática, isto é, uma teoria que se erguendo da prática pudesse retornar a ela na forma de um conhecimento menos ingênuo da realidade social. Elencada a partir das experiências vivenciadas pelo autor durante a guerra pela independência argelina nos anos sessenta, Bourdieu apresenta-se na história do pensamento francês como uma possibilidade de superação das visões subjetivistas e objetivistas das teorias sociais da época. Com tal ensejo, dedica-se a construir uma teoria que vinculasse o agente social e o meio social, o qual é entendido como a rede de relações sociais historicamente constituídas, cuja manutenção, modificação ou abalo ocorre pelas ações dos agentes. Partindo do princípio de que nada no mundo social é evidente ou natural, mas resultado de uma construção humana constante e permanente, a categoria da ação torna-se o ponto fulcral com o qual persegue a compreensão dos mecanismos de reprodução das desigualdades sociais. Disso resulta uma complexa teoria social, cujo núcleo duro é a inter-relação das noções habitus, campo e capital, os quais são conceitos operacionais e se constituem em seu método de análise social. Contudo, a fim de alcançar o objetivo de compreender o espaço da OMC como sendo um espaço social de luta do liberalismo, nos deteremos na noção de campo da teoria bourdieusiana.

Inicialmente abordada no artigo Champ intellectuel et projet créateur (1966), a noção de campo bourdieusiana se consolida nos anos setenta quando é conceituado como um espaço social definido por uma autonomia relativa e uma estrutura vinculada à uma configuração específica de agentes oportunizada pela posição que ocupam ao adentrar em dado campo social (LEBARON \& Le ROUX, 2013; SAPIRO, 2017). Dessa forma, os campos são vistos como espaços estruturados pelas relações objetivas entre as posições que os constituem e nas quais os agentes são introduzidos, algo que lhe confere a característica de ser um "[...] locus de relações de força - não somente de significado - e de lutas que assinalam sua transformação [...]"4 (BOURDIEU, 2008b, p. 142). Compreendido como espaço social, o campo se configura a partir da rede de relações objetivas entre

4 Tradução dos autores. No original: “[...] locus de relaciones de fuerza - no sólo de significado - y de luchas que apuntan a transformarlo [...]”. 
as posições ocupadas pelos agentes, as quais são objetivamente definidas por sua existência e pelas determinações que impõem aos agentes ou instituições que as ocupam (BOURDIEU, 2008b).

Dotados de sua própria lógica, de sua própria história, assim como de sua própria linguagem e de modos específicos de procedimentos, as transformações possíveis das relações hierarquizadas advindas das desigualdades de condições que conduzem as relações objetivas dos agentes e seus posicionamentos em dado campo ocorrem pelas distâncias, assimetrias e brechas existentes entre as diversas forças que ali se confrontam (BOURDIEU, 2002; BOURDIEU \& WACQUANT, 2008b). Compreendido como um espaço de lutas e de forças advindas das posições ocupadas pelos agentes, o campo é visto como um espaço social dinâmico e semiautônomo (THOMSON, 2018). Dinâmico porque ao se constituir em espaços de forças e de lutas, os agentes permanentemente elaboram estratégias ora para manter ora para modificar a hierarquia existente em dado campo; semiautônomos pela relação de interdependência que se estabelece entre os diversos campos que compõem o mundo social.

Nesse sentido, um campo se constitui por meio de posições desiguais, as quais tecem a trama de relações hierárquicas entre os agentes partícipes em dado campo social. Por um lado, tais relações são consideradas como polo atrativo para lutas em prol de multiplicar o capital relevante para o campo e, por outro lado, pela luta para conservá-lo. Tal jogo de forças encontra-se alicerçado no entendimento bourdieusiano de que um campo se estrutura em torno das forças exercidas pelas relações constantes e permanentes de desigualdade que se exercem no interior do campo, cuja existência de posições dominantes e posições dominadas impulsionam as lutas para transformar ou conservar esse jogo de forças (BOURDIEU, 2008a). A luta por posições, no entanto, estabelece-se por meio de relações silenciosas de cumplicidade entre os agentes e a doxa do campo a fim de evitar tanto a expulsão do agente como busca manter o status quo do campo em questão.

Doxa na teoria bourdieusiana é compreendida como "[...] aquilo sobre o qual todo mundo está de acordo, está tão de acordo que não se fala sobre isso, o que está fora de questionamento, o que está dado" 5 (BOURDIEU, 2002, p. 83). Refere-se ao conjunto de crenças pré-reflexivas, percepções e opiniões vinculadas ao campo em questão e compartilhadas porque herdadas e internalizadas pelos agentes; e não questionadas por serem tidas como evidentes e inevitáveis porque naturalizadas. Segundo Deer (2018, p. 157) “[...] ela determina a estabilidade das estruturas sociais objetivas através do modo como elas são reproduzidas e se reproduzem nas percepções e práticas dos agentes [...]”. Portanto, a cumplicidade silenciosa entre agente e campo é o que permite o reconhecimento tácito do valor e dos princípios que regem o senso prático dos agentes, ou seja, aquilo que é apreendido pela mente e pelo corpo e que se encontra no impensado das ações sociais (BOURDIEU, 2008b). Significa compreender que o que alimenta a tessitura das relações ali existentes e, por fim, a manutenção de posições dominantes e dominadoras encontra-se em tal

5 Tradução dos autores. No original: «[...] c'est ce sur quoi tout le monde est d'accord, tellement d'accord qu'on n'en parle même pas, ce qui est hors de question, qui va de soi». 
cumplicidade de maneira velada e silenciosa da qual participam todos aqueles que entram em um campo social. Contudo, Bourdieu (1990) não exclui as ações conscientes, pensadas e analisadas estrategicamente para lutar seja pela conservação das relações estabelecidas seja pela mudança, a qual será sempre limitada ao acordo tácito de proteção da existência do campo.

Compreende-se, com isso, que o reconhecimento exigido daqueles que adentram em um dado campo social não está vinculado à aceitação das regras do jogo estabelecidas, mas está vinculado principalmente à assimilação do sentido do jogo que caracteriza o campo. Para Bourdieu (1990), o sentido do jogo diz respeito ao conhecimento da necessidade e da lógica imanente ao jogo, tal conhecimento apreendido e assimilado pelas práticas sociais permitem a participação dos agentes por meio da obediência não às regras e normativas explícitas, mas pela obediência à regularidade que caracteriza o jogo praticado no campo social. ${ }^{6}$ Por outro lado, o jogo está relacionado às condições que dado agente possui para enfrentar as forças já estabelecidas e lutar pela ascensão na hierarquia do campo no qual está inserido.7 Tais condições se referem ao volume e à estrutura do capital de cada agente no momento em que adentra no campo, ao qual se soma sua trajetória social, a evolução do volume e da estrutura de seu capital e a constituição de seu habitus (BOURDIEU, 2008b).

Na relação entre agente e campo, o capital é o elo que permite estabelecer relações de poder por meio da composição de forças entre agentes e campo. Significa compreender que quanto mais capital consoante ao capital específico de dado campo melhores condições tal agente possui de ascensão, poder de decisão, intervenção e mudanças nas relações ali existentes. Convém ressaltar, no entanto, que o capital bourdieusiano não se limita ao capital econômico, cuja importância é reconhecida pelo autor, mas é acrescido de três outras formas: cultural, social e simbólico (BOURDIEU, 1986). Assim, a relação de força impulsionada pelo capital dos agentes possibilita compreender os campos sociais como espaços de lutas, cujo reconhecimento está vinculado aos outros agentes partícipes do campo, os quais referendam ou não o conjunto de ações e práticas de dado agente.

A posse de capital vinculado ao capital específico e ao reconhecimento ou não do mesmo pelos agentes do mesmo campo é o que alimenta as relações de poder que se instituem por meio da

\footnotetext{
${ }^{6}$ Convém ressaltar que Bourdieu diferencia regra de regularidade, pois para ele existem princípios de regulação que regulam a regularidade das práticas sociais, as quais são partes imanentes do jogo praticado nos campos sociais. Assim, a obediência às regularidades implica uma obediência impensada, pois faz parte do escopo da visão naturalizada que tais ações carregam consigo. Como exemplo, o autor se refere aos "[...] herdeiros ricos que regularmente se casam com caçulas ricas. Isso não quer dizer que seja regra, para os herdeiros ricos, desposar caçulas ricas. Mesmo que se possa pensar que desposar uma herdeira (mesmo rica, e a fortiori uma caçula pobre) seja um erro, e até, por exemplo, aos olhos dos pais, uma falta." (BOURDIEU, 1990, p. 83). Apesar de não existir uma regra explícita que estabeleça tal conduta, é a regularidade prática das condutas que impulsionam sua repetição geração após geração.

7 A luta para ascender na hierarquia do campo significa a luta por ocupar uma posição de dominação. Para Bourdieu (2000, p. 238), «Le dominant est celui qui occupe dans la structure une position telle que la structure agit en as faveur. [...] définissent les regularités et parfois la règle du jeu, imposant la définition des atouts la plus favoravle à leurs intérêts et modifiant tout l'environnement des autres [...]».
} 
desigualdade, a qual está vinculada ao volume e à estrutura do capital dos agentes. Embora separados pela desigualdade na posse de seus capitais, o movimento dinâmico no interior do campo possui o limite da obediência a uma lei tácita e implícita que se encontra no fundamento dos campos sociais: a de proteger a sua existência contra a destruição. Conforme Bourdieu (2002), as possíveis subversões nos campos sociais a fim de realizarem rupturas se tornam limitadas, pois a tentativa é a de não colocar em risco não somente a pertença ao campo em questão, mas também a existência do próprio campo.

\section{ORGANIZAÇÃO MUNDIAL DO COMÉRCIO}

Nos estertores do fim da II Guerra Mundial (1939-1945), a Conferência de Bretton Woods, em 1944, sob liderança dos Estados Unidos, é realizada com quarenta e quatro países inclusive o Brasil. Nessa Conferência, instituições são criadas como o Fundo Monetário Internacional e o Banco Internacional para Reconstrução e Desenvolvimento (BIRD), bem como se estabelece o padrão dólar-ouro como parâmetro do sistema cambial. Essas iniciativas constituíam o delineamento da disputa em curso entre os Estados Unidos e a ex-União das Repúblicas Socialistas Soviéticas, com seus respectivos modelos político-econômicos, de um lado, o capitalismo, de outro lado, o socialismo. Na esteira dessas iniciativas e da disputa em curso pelo poder mundial, ocorre a Conferência das Nações Unidas sobre Comércio e Emprego, em Havana, Cuba, em 21 de novembro de 1947. A denominada Conferência de Havana propõe a criação da Organização Internacional do Comércio (OIC) e firma a Carta de Havana, em 24 de março de 1948. A carta constitutiva, entretanto, nunca entrou em vigor, pois os Estados Unidos não a ratificaram. O fracasso da criação da OIC não impediu o ímpeto do movimento do liberalismo econômico e comercial. Dessa forma, em 1947, por iniciativa de vinte e três países incluindo o Brasil, estabelece-se o chamado Acordo Geral sobre Tarifas e Comércio, mais conhecido na denominação em inglês, General Agreement on Tariffs and Trade (GATT). Em vigor desde o dia primeiro de janeiro de 1948, o GATT torna-se o principal mecanismo internacional de equilíbrio do comércio internacional (COSTA, 2011).

Ao se tornar o principal arcabouço de regras e normas, o GATT desenvolve funcionamento próprio em que os países reuniam-se de tempos em tempos em prol de rever, avaliar, discutir e propor o delineamento do comércio internacional. Essas reuniões traduziam-se em rodadas de negociação em prol dos princípios de redução substancial das tarifas e outras barreiras ao comércio, bem como da eliminação do tratamento discriminatório no comércio internacional. Foram oito rodadas de negociação listadas a seguir: Genebra (1947), Annecy (1949), Torquay (1950-1951), Genebra (1955-1956), Dillon (1960-1961), Kennedy (1964-1967), Tóquio (1973-1979) e Uruguai (1986-1993). As primeiras cinco rodadas concentraram-se no tema das tarifas, mas as três últimas rodadas incorporaram novos temas como atualização das demandas ocasionadas pela dinâmica da 
revolução técnico-científica em conjunto com a incorporação crescente de países de baixo e médio desenvolvimento econômico ao fluxo do comércio internacional. Como consequência, a Rodada Kennedy (1964-1967) lidou com tarifas e antidumping, a Rodada Tóquio (1973-1979) tratou de tarifas, medidas não tarifárias e cláusula de habilitação e a Rodada Uruguai (1986-1993) ampliou significativamente o leque de temas para, além das tarifas, debater sobre agricultura, serviços, propriedade intelectual, medidas de investimento, novo marco jurídico e a criação da Organização Mundial do Comércio.

Observa-se que as oito rodadas de negociação, a despeito da ampliação dos temas negociados, mantinham o princípio liberal econômico e comercial centralizado na compreensão de reduzir tarifas, barreiras ao comércio e eliminar tratamento discriminatório no comércio internacional. Desse modo, a finalização da Rodada Uruguai (1986-1993) constitui o marco para que o sistema multilateral de comércio institucionalize-se com vistas a ser facilitador da expansão da proposta liberal econômica. Ressalta-se a crescente incidência normativo-técnico a cada encaminhamento negociador em uma proximidade do princípio liberal econômico e comercial com o liberalismo de linha jurídica (CASTRO, 2012).

A Ata Final do Acordo advinda da Rodada Uruguai, assim, é aprovada em 15 de abril de 1994, em Marraquexe, Marrocos, e o denominado Acordo de Marraquexe apresenta, com isso, a criação da OMC, um preâmbulo, dezesseis artigos e quatro anexos (THORSTENSEN, 2003). No escopo institucional proposto, os Anexos dividem-se da seguinte forma:

\section{QUADRO 1 - ANEXOS DO ACORDO DE MARRAQUEXE}

\begin{tabular}{|c|c|}
\hline Anexo 1 & $\begin{array}{l}\text { Anexo 1A: } \\
\text { GATT 1994 que incorpora vários acordos de comércio de bens inclusive as Medidas de } \\
\text { Investimentos Relacionadas ao Comércio (na sigla em inglês, TRIMs); } \\
\text { Anexo 1B: } \\
\text { Acordo Geral de Comércio de Serviços (na sigla em inglês, GATS); } \\
\text { Anexo 1C: } \\
\text { Aspectos da Propriedade Intelectual Relacionados ao Comércio (na sigla em inglês, TRIPS). }\end{array}$ \\
\hline Anexo 2 & Regras e procedimentos para a solução de controvérsias (na sigla em inglês, DSU). \\
\hline Anexo 3 & Estabelece o Mecanismo de Revisão de Política Comercial (na sigla em inglês, TPRM). \\
\hline Anexo 4 & $\begin{array}{l}\text { Composto por quatro acordos plurilaterais sobre comércio de aeronaves civis, laticínios, } \\
\text { carnes bovinas e compras do setor público. }\end{array}$ \\
\hline
\end{tabular}

Fonte: Thorstensen (2003).

Destaca-se que os signatários do Acordo devem seguir o denominado princípio single undertaking em que os acordos comerciais multilaterais concentrados nos Anexos 1, 2 e 3 obrigam a todos os membros, enquanto que os acordos comerciais plurilaterais do Anexo 4 tem efeitos somente aos seus signatários. Ressalta-se que, atualmente, os acordos plurilaterais referentes aos produtos lácteos e à carne bovina não estão mais em vigor. 
O Acordo de Marraquexe estabelece também a estrutura, as funções, a personalidade jurídica e o processo decisório da OMC. Desse modo, a OMC entrou em vigor em $1^{\circ}$ de janeiro de 1995 com sede em Genebra e alicerça o sistema multilateral do comércio no princípio da nação mais favorecida, no princípio do tratamento nacional e no princípio da transparência. Em termos estruturais, a OMC é constituída de Conferência Ministerial (composta por Ministros de Relações Exteriores ou de Comércio Exterior), de um Conselho Geral (representantes permanentes na sede de Genebra), de Conselhos para o Comércio de Bens, de Serviços e de Propriedade Intelectual, de diversos Comitês e de um Secretariado (MESQUITA, 2013).

A institucionalização do espaço negociador conferiu aos membros da OMC um espaço para a negociação e a ampliação do multilateralismo comercial em prol do liberalismo econômico. Nota-se, ao longo de mais de duas décadas de existência da OMC, a crescente inclusão de membros com destaque para a entrada da China em 2001 e a Rússia em 2012. Ressalta-se a participação da União Europeia desde a criação da OMC, mas legalmente participava como Comunidade Europeia até 2009 e depois como União Europeia. A OMC favorece, com isso, a economia política internacional no viés da interdependência pragmática por meio da interdependência comercial dos Estados junto com a operacionalização da instituição em prol de um mercado comercial liberal (CASTRO, 2012).

Atualmente, a OMC é composta por 164 membros, mas, para o presente artigo, propõe-se concentrar uma análise sobre como Estados Unidos, China e União Europeia conduzem como agentes a participação nessa instituição. Essa participação compreendida como agentes comprometidos com os princípios da OMC coadunados com uma disputa econômica e política entre os três agentes supracitados nesse ambiente institucional, bem como a reiteração dos interesses comerciais e mercadológicos consubstanciados no liberalismo econômico.

\section{A OMC COMO ESPAÇO DE LUTA DO LIBERALISMO: REFLEXÕES CONCLUSIVAS}

A concepção da criação de um organismo instituído de propósito liberal econômico é consequência do término da II Guerra Mundial. O fracasso da criação da Organização Internacional do Comércio não impediu esforços dos países imbuídos na busca pelo equilíbrio no comércio internacional de se utilizar do GATT em prol do liberalismo econômico. Desse modo, as rodadas de negociação constituíram-se em incrementos do comércio internacional conjuntamente com manutenção do princípio liberal econômico e comercial. No intuito de valer-nos das ferramentas teóricas bourdieusianas, duas dimensões podem ser realçadas na trajetória histórica da formação da atual OMC: o interesse norte-americano na liderança comercial, ou seja, um interesse econômico conjugado com um interesse político dirigido ao incremento da Guerra Fria por meio da imposição do modelo liberal econômico que defendia. 
A análise social bourdieusiana acarreta conhecer não somente o percorrido histórico, mas especialmente o contexto social, econômico e político no qual dado agente social se reúne a outros agentes sociais a fim de elencar o nascedouro de um campo social. Estruturando-se ao longo do tempo por meio de relações objetivamente constituídas, a década de 1990 oportuniza um processo de institucionalização do espaço negociador com a criação da Organização Mundial do Comércio. Como consequência, os membros da OMC engajam-se tanto em negociações como também se empenham na ampliação do multilateralismo comercial para que o liberalismo econômico, antes um princípio-guia, se tornasse um formalismo processual institucional. Dessa forma, temas e acordos no âmbito da OMC adquiriram escopo alargado e, ao mesmo tempo, atraíram as atenções e disputas econômicas e políticas por parte dos Estados Unidos, da China e da União Europeia.

Contrário ao objetivo de facilitar as negociações e evitar o protecionismo comercial, a OMC tem se caracterizado por ações que buscam beneficiar em primeiro lugar seus principais agentes. A disputa entre Estados Unidos, União Europeia e China se caracteriza por acordos tácitos disfarçados de incômodos ocasionais que incrementam o jogo existente, chamando a atenção mundial para momentos de tensão, principalmente protagonizados pela relação Estados Unidos e China, os quais, na prática, não alteram o status quo das relações pré-estabelecidas. Ao contrário, as ameaças que algumas vezes são realizadas não chegam ao ponto de serem cumpridas, pois conforme vimos na teoria bourdieusiana, o campo oferta um espaço de luta e de conflito até o limite em que não seja ameaçada a sua existência. Portanto, não há interesse em promover rupturas que ameacem tanto a presença do agente como o campo em questão. As tensões e conflitos surgidos entre os agentes se inserem no escopo do entendimento da OMC como um espaço social configurado por lutas e conflitos mediados pelos interesses de seus membros. Em outros termos, tais tensões e conflitos fazem parte do jogo ali instaurado o que possibilita aos agentes que ocupam posições dominantes manterem tal posição.

A ascensão econômica chinesa nos anos noventa criou a expectativa mundial de que mudanças significativas ocorreriam no modelo liberal econômico que rege o jogo das relações na OMC. O início dos anos dois mil, no entanto, vê a consolidação do poder econômico chinês, o que permite posicionar o gigante asiático no campo da OMC como o terceiro agente com poder econômico efetivo, incrementando seu capital simbólico e abrindo para os outros países a possibilidade de investimentos para além da dupla Estados Unidos - União Europeia. Assume, portanto, uma posição relevante no espaço junto daqueles que dominam o campo. Contrariando as expectativas, os chineses não se posicionam na contramão do liberalismo econômico. Na esteira bourdieusiana, os chineses assimilam o jogo pré-estabelecido pelas relações objetivas que constituem o campo, incorporam as regras existentes à sua prática, assumem uma posição dominante e ampliam seu próprio capital econômico de modo a aumentar também o capital político. Pode-se colocar que a China aprendeu e apreendeu a maneira como as relações sociais estavam estabelecidas, o que lhe permitiu agir em prol dos seus próprios interesses, inclusive a luta na busca 
do reconhecimento de seus pares, um elemento relevante na análise bourdieusiana. Em suma, o senso do jogo existente na OMC é assimilado pelos chineses, cujas negociações objetivas são realizadas dentro dos limites possíveis de alteração que as regras do campo permitem.

Ao mesmo tempo, sua condição política passa a ser desconsiderada como relevante no âmbito das disputas comerciais, ou seja, o regime político alicerçado nos preceitos comunistas não é alvo nem de críticas nem de rejeição para sua participação nesse ambiente. O que se busca realçar é que a dissociação entre a China como economia de mercado e a China comunista é convenientemente desconsiderada seja pelos pares da OMC seja pelos próprios chineses, os quais não se valem de seus preceitos políticos para promover possíveis polos de discussão. Na composição da OMC enquanto um campo social pode-se considerar que o regime político dos agentes dominantes torna-se paulatinamente o elemento impensado do campo, um elemento que inicialmente pode ter gerado incômodos, mas é convenientemente silenciado ao longo do tempo. E, com isso, as ações chinesas no âmbito da OMC passam a ser regidas pelo liberalismo econômico, o fio condutor que tece as relações entre agentes - países membros -, o qual não somente elencou a sua formação, mas que encontra eco em todos seus participantes. Em outros termos, ao compreender a OMC como um espaço de lutas do liberalismo significa compreender que as lutas, as disputas e os conflitos não se vinculam a questionar tal liberalismo, mas a busca pela prevalência do interesse de um agente sobre outros agentes ou a luta pelo convencimento dos agentes de suas propostas.

$\mathrm{Na}$ visão social bourdieusiana, o campo social se caracteriza como um espaço de lutas, de disputas e de conflitos por posições seja para manter seja para modificar as relações que o constituem. Ainda conforme tal visão, tais movimentos ocorrem dentro da premissa da preservação do próprio campo, ou seja, a busca pela modificação encontra o limite da preservação do status quo do campo social. Com tal perspectiva, pode-se dizer que o espaço de lutas no caso da OMC se caracteriza mais pela manutenção da posição dos três principais agentes, o que terminou frustrando as expectativas de que a China viesse a dominar tal espaço ou no mínimo viesse a colocá-lo em xeque com sua presença. Com isso, o que destacamos é que na complexa relação de interesses comerciais, as disputas políticas assumem um papel relevante, pois politicamente parece não haver interesse na existência de um agente dominador, mas sim uma tríade dominante em relação aos demais membros da organização. Nesse sentido, o jogo praticado circula entre a tríade em torno da qual os demais agentes - países membros - se posicionam, mas perante a qual suas ações em prol de concretizar seus propósitos ou efetivamente alterar a hierarquia estabelecida são limitadas. Tal disputa desigual devida às posições diferenciadas dos agentes dotados de capital econômico, político e simbólico próprios e inseridos em uma rede relacional que os antecede, quando visto sob a lente bourdieusiana, acarreta refinar a análise das relações estabelecidas entre as duas dimensões que operam no interior da OMC: a tríade dominante e os demais países membros.

O artigo se propôs demonstrar a OMC como um espaço de luta e de conflitos alicerçado no fio condutor que atravessa as relações objetivas ali estabelecidas e que constroem tal espaço social: 
o liberalismo econômico. Para alcançar o objetivo proposto, destacou-se a noção de campo da teoria social bourdieusiana a qual permite abrir outra vertente de análise dos organismos internacionais. Com isso, a OMC é analisada reflexivamente como um campo social, cujo espaço se constitui pelas relações objetivas em torno de um propósito comum declarado: facilitar as negociações internacionais entre seus membros. Contudo, pode-se colocar que o interesse velado era o de disseminar o modelo liberal econômico, colocando os Estados Unidos como país-modelo a ser seguido. Tal colocação se alicerça no histórico de formação de organismos internacionais vinculados ao comércio, cuja proposta foi liderada pelos Estados Unidos nos anos quarenta. Portanto, no impensado do espaço social da OMC, existe desde o início o empenho em estabelecer negociações à luz do liberalismo econômico ao qual os países membros aderem tacitamente. Disto decorre a adesão da China à luz da divisão interessada que oferta entre uma economia de mercado e um regime político comunista, o que contribui para incrementar a doxa que constitui o campo. A doxa entendida como o conjunto de crenças, de percepções e de opiniões, uma espécie de enredo que se apreende e se aprende por meio das relações sociais que se instauram, torna-se um elemento relevante para compreender a cumplicidade tácita dos agentes em torno da dissociação entre economia e regimes políticos.

Na concepção bourdieusiana, a constituição de um campo social dá-se ao longo do tempo com a conjunção de interesses e da conveniência dos agentes em torno de um objetivo comum, as relações alicerçadas nos capitais econômico e simbólico dos agentes tecem relações de força por meio das quais a hierarquia entre os agentes - países membros - se constroem. Com isso, o espaço é estruturado inicialmente entre Estados Unidos e a Comunidade Europeia, os quais ditam as regras e normativas do comércio internacional até os anos noventa. Prática que se manteve com a consolidação da União Europeia no final do século passado e a entrada da China no início dos anos dois mil. Tais situações, contudo, ocorreram em um novo cenário político mundial, pois com a queda do muro de Berlim e a extinção da União Soviética, o fim da Guerra Fria fora iminente e a globalização tornou-se uma realidade. Dessa forma, os anos noventa inauguram um cenário político e econômico ímpar, cuja prevalência do liberalismo econômico não encontra opositores. Em outros termos, as negociações em tal espaço giram em torno desse princípio que une todos os países membros ali partícipes, cuja conveniência ou inconveniência é ofertada pela tríade que domina esse espaço exigindo dos demais agentes a busca por brechas para conseguirem ter voz ativa nos principais temas de interesse variado.

A entrada da China na OMC ocorre em um novo contexto, um contexto social, histórico e político que instigava uma abertura em direção à perspectiva de novos mercados e a ampliação das relações comerciais. Considerando que a exigência no interior do campo é a de se alinhar ao jogo existente a fim de pertencer ao mesmo, a China adere ao senso do jogo do qual não somente participa, mas também termina por lhe propiciar a pertença à tríade de agentes que ocupam a posição de dominadores. Tal tríade exige dos outros agentes - países membros - ações que em sua grande 
maioria visam à manutenção do status quo do campo. Em outros termos, as regras e normativas elaboradas no comércio internacional são referendadas e pouco contestadas pelos demais agentes países membros -, cujo capital econômico e simbólico não são suficientes para ascender na hierarquia e, principalmente, alterar o que muitas vezes não lhes favorece. A luta desigual entre os agentes - países membros - revela, por um lado, as relações de dominação estabelecidas no interior das negociações internacionais e, por outro lado, destaca que tal desigualdade pode ser vista como o reflexo das desigualdades sociais que caracterizam as sociedades humanas. Em suma, ao se colocar a OMC como um espaço de luta do liberalismo, ressalta-se que por trás das diversas discussões em torno de negociações referentes ao comércio internacional existe não somente a reprodução de um modelo econômico, mas especialmente a aceitação de um modelo econômico por parte de todos aqueles que participam desse campo.

*Artigo recebido em o9 de fevereiro de 2021, aprovado em 11 de maio de 2021.

\section{REFERÊNCIAS}

BOURDIEU, Pierre. Da regra às estratégias. In: Coisas Ditas. São Paulo: Brasiliense, 1990.

BOURDIEU, Pierre. Quelques propiétés des champs. In: Paris: Les Éditions de Minuit, 2002.

Questions de sociologie.

BOURDIEU, Pierre. Pour une sociologie des sociologues. In: Questions de sociologie. Paris: Les Éditions de Minuit, 2002.

BOURDIEU, Pierre. Sur la télévision: suivi de L'emprise du journalisme. Paris: Raisons d'agir, 2008a.

BOURDIEU, Pierre. Las formas de capital (1986). Traducción de Rubén U. Alvarado. Disponível em: https://www.academia.edu/1360865/LAS FORMAS DE CAPITAL. Acesso em: 15 de dezembro de 2020.

BOURDIEU, Pierre. Principes d'une anthropologie économique. In: Les structures sociales de l'économie. Paris: Seuil, 2000.

BOURDIEU, Pierre \& WACQUANT, Loïc. Una invitación a la sociología reflexiva. Buenos Aires: Siglo XXI editores, 2008b.

CASTRO, Thales. Teoria das relações internacionais. Brasília: FUNAG, 2012.

CONFERÊNCIA DE HAVANA SOBRE COMÉRCIO E EMPREGO. New York: The United Nations, 1948. Disponível em: https://treaties.un.org//doc/source/docs/E CONF.2 78-E.pdf . Acesso em: 01 nov. 2020. 
COSTA, José Augusto Fontoura. Do GATT à OMC: a perspectiva neoliberal institucionalista. Universitas Relações Internacionais, Brasília, v. 9, $\mathrm{n}^{0}$ 2, p. 25-53, jul./dez. 2011, Disponível em:

https://www.publicacoesacademicas.uniceub.br/relacoesinternacionais/article/view/1413/1494. Acesso em: 07 nov. 2020.

DEER, Cécile. Doxa. In: GRENFELL, Michael. (ed.). Pierre Bourdieu: conceitos fundamentais. Tradução de Fábio Ribeiro. Petrópolis: Vozes, 2018.

HOBSBAWM, Eric. A Era das revoluções: Europa 1789-1848. Rio de Janeiro: Paz e Terra, 2002.

HOBSBAWM, Eric. A Era do capital, 1848-1875. Rio de Janeiro: Paz e Terra, 1996.

HOBSBAWM, Eric. Era dos extremos: o breve século XX: 1914-1991. São Paulo, Companhia das Letras. 2003.

LEBARON, Frédéric. \& Le ROUX, Brigitte. Géométrie du champ. In: Actes de la recherche en sciences sociales, $\mathrm{n}^{0}$ 200, 2013, p. 106-109. Disponível em: https://www.cairn.info/revue-actes-dela-recherche-en-sciencessociales . Acesso em: 30 de outubro de 2020.

MESQUITA, Paulo Estivallet de. A Organização Mundial do Comércio. Brasília: FUNAG, 2013. PECEQUILO, Cristina. A política externa dos Estados Unidos. Porto Alegre: Editora da UFRGS, 2003.

SAPIRO, Gisèle. Champ: elaboration, usages et circulations du concept. In: Notice, Politika, 2017. Disponível em: https://www.politika.io/fr/notice/champ . Acesso em 02 de novembro de 2020.

THE TEXT OF THE GENERAL AGREEMENT ON TARIFFS AND TRADE. Geneva: The World Trade Organization, 1986. Disponível em: https://www.wto.org/english/docs e/legal e/gatt47.pdf . Acesso em: 11 nov. 2020.

THE WORLD TRADE ORGANISATION. Geneva: 2019. Disponível em: www.wto.org . Acesso em: 14 nov. 2020.

THOMSON, Patrícia. Campo. In: GRENFELL, Michael. (ed). Pierre Bourdieu: conceitos fundamentais. Tradução de Fábio Ribeiro. Petrópolis: Vozes, 2018.

THORSTENSEN, Vera. OMC - Organização Mundial do Comércio. São Paulo: Aduaneiras, 2003. 